- ACORN Australan college of | JOURNAL OF PERIOPERATIVE NURSING

\title{
Who's under the mask? Colour-differentiated identification labels for perioperative staff
}

Follow this and additional works at: https://www.journal.acorn.org.au/jpn

Part of the Health Services Administration Commons, Health Services Research Commons, Perioperative, Operating Room and Surgical Nursing Commons, and the Surgery Commons c) (7)

This work is licensed under a Creative Commons Attribution 4.0 License.

\section{Recommended Citation}

Bentley, Diana (2020) "Who's under the mask? Colour-differentiated identification labels for perioperative staff," Journal of Perioperative Nursing: Vol. 33 : Iss. 2 , Article 7.

Available at: https://doi.org/10.26550/2209-1092.1088

https://www.journal.acorn.org.au/jpn/vol33/iss2/7

This Project report is brought to you for free and open access by Journal of Perioperative Nursing. It has been accepted for inclusion in Journal of Perioperative Nursing by an authorized editor of Journal of Perioperative Nursing. 
Diana Bentley

Patient Journey Facilitator

BN, GradCert Anaesthetic \& PACU Nursing

\title{
Who's under the mask? Colour- differentiated identification labels for perioperative staff
}

\begin{abstract}
Staff identification in the perioperative environment is difficult when all staff, students and visitors wear the same attire. All attire needs to be laundered to national standards for infection control governance and consequently attire cannot be individualised. In emergency situations it is also difficult to identify the roles of all staff with standard methods of identification.

The aim of the 'Colour-differentiated identification labels' project was to improve identification of all staff and visitors in the perioperative environment with the intended result being improved communication and safety among staff, patients and visitors. The project began in February 2018 with project leads Diana Bentley and Wendy Howard in the anaesthetics department of the perioperative service in a New South Wales (NSW) public hospital. Disposable identification (ID) labels were initially trialled with the anaesthetic staff for three months. ID labels were designed and printed to give a more uniform appearance. The trial period proved highly successful so the project expanded to include the whole perioperative service at the hospital. Disposable ID labels were subsequently developed that included staff members' roles, and teams were differentiated by specific colours.
\end{abstract}

\section{Identified problem}

The project leads identified that there was a significant safety and communication risk in the perioperative environment arising from the potential for misidentification of staff, students and visitors. When these people are all clothed in identical attire there is no way of identifying a person's role. This poses a significant safety risk, especially in larger organisations and emergency situations ${ }^{12}$.

\section{Proposed solution}

Concern around misidentification in the perioperative environment and wanting to improve safety started a 'theatre cap challenge' in which perioperative staff were encouraged to display their name on their cap³. The project team decided to take this a step further and implement disposable colour-differentiated ID labels for each perioperative team.
Effective communication within the perioperative environment is essential for achieving patient safety. A large part of perioperative communication is non-verbal, and one type of nonverbal communication is 'object communication', such as colours. A colour contains a coded message and is a visual cue for an immediate identification of personnel. By choosing specific colours to identify each of the various teams within the perioperative service, the ID labels have the potential to optimise perioperative communication between staff and with patients. This is of the utmost importance in the perioperative environment especially during emergency events².

\section{Implementation strategies and challenges}

The initial trial began with the anaesthetic team (nursing and medical) and ran for approximately three months. During this time, 


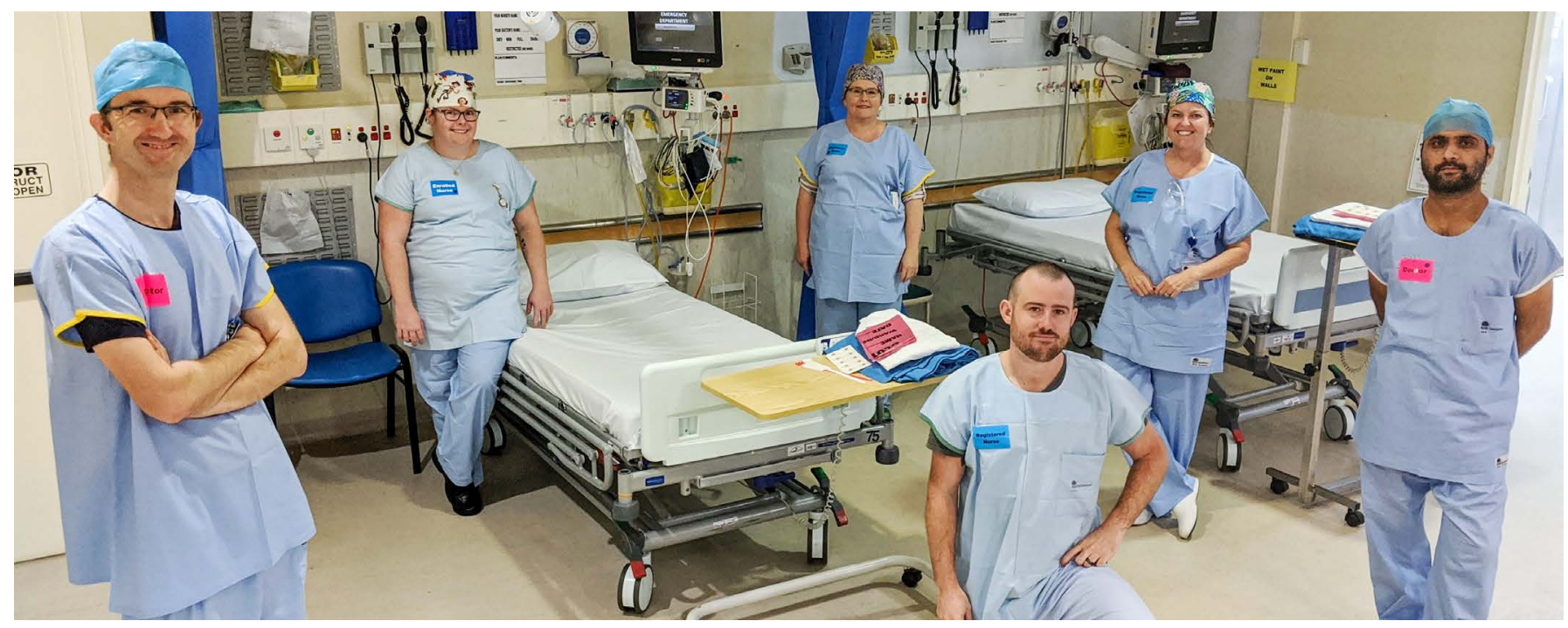

Emergency department team wearing colour-differentiated ID labels

verbal feedback was collected from students and regular visitors to the perioperative service, i.e. ward staff, company educators and representatives. Regular verbal feedback was also provided by participating anaesthetic staff to the project leads throughout the initial trial. After the initial trial was completed, assessments of the staff in the perioperative service were conducted to see what their experience was regarding the use of colour-differentiated ID labels. The information gathered from these assessments indicated that the climate for change and overall acceptance of this intervention in our perioperative service was good. The assessments also helped us to provide targeted information and education sessions prior to implementing the project in the whole perioperative service. We used a combination of formal education processes such as education sessions using a PowerPoint presentation as well as an informal 'quick sell' which was a 30-second summary of colour-differentiated ID labels and the benefits of using them. Being positive and passionate in our 'sell' was central to the project's success'.
One of the challenges encountered was getting uninterrupted time with surgeons to explain and discuss the purpose and benefits of the project with them. This issue was later addressed by the nurse manager (NM) of the hospital's perioperative service who agreed to be a champion for the project. The project was tabled for discussion and endorsement at a regular meeting of surgeons and the executive. At this meeting, the NM explained the purpose of the project, outlining the safety and communication benefits and answering questions. The surgeons, including the head of the department (HOD) of surgery, agreed to endorse and support the wearing of colour-differentiated ID labels. The endorsement from both the anaesthetic and surgical HODs, as well as nursing management, meant that compliance was expected by all perioperative staff.

One of the valuable lessons learnt from this project was the importance of planning and preparation to ensure uptake, success and longevity. The project team was both passionate and enthusiastic about the project and the positive changes that it could bring to the department. On reflection, some of the barriers initially encountered were due to the fact that not enough time was given to laying the groundwork and gathering data. The project leads have since realised that having a formal way of collecting feedback is vitally important to being able to quantifiably measure the success of a project. Using a pre-implementation questionnaire and collating the information would have provided quantifiable data and evidence of the identified problem. This is something that has been rectified for future implementation of the project in other perioperative services and is included in the implementation package.

\section{Program successes and opportunities for enhancement}

Some of the interdepartmental successes that have come from the project are the ability for the hospital resuscitation team to be able to quickly and clearly identify all staff in the perioperative service (their role, team and name) when they have been called to assist in an emergency. This has resulted in reduced confusion and less unnecessary stress and frustration for all involved. 
At the end of 2019, an interdepartmental crisis management simulation session was carried out between the emergency department, birthing suite, perioperative service and intensive care unit. Feedback was received from the participants involved in the simulation session that the wearing of colour-differentiated ID labels had definitely enhanced communication and safety during serious incidents.

One of the latest initiatives using colour-differentiated ID labels came about due to COVID-19. The staff in all the emergency departments in the local health district began wearing theatre scrubs to decrease the risk of transmitting the virus to the community via their uniforms. Staff would change into scrubs when they arrived at work and change out of them before they left work. The project leads were contacted by the nurse unit manager (NUM) from one of the emergency departments who had concerns over staff misidentification and the potential safety and communication risks this posed. They worked with the emergency department NUM to translate the work from the perioperative environment to the emergency department, developing roles and team colours for the ID labels. There was also an added advantage in the current situation of COVID-19 and the infection control measures that need to be taken with the labels being disposable.

\section{Recommendations}

The colour-differentiated ID labels project has moved from the implementation phase at the NSW public hospital and is now in maintenance phase. Early in 2020 the project is being rolled out to other perioperative services within the local health district. There has also been interest from some Sydney and Victorian perioperative services to implement the project at their sites. An implementation package has been created by Diana Bentley to assist with planning, education, implementation and maintenance of the project in your workplace.
If you are interested in implementing this project in your perioperative service, please contact the project leads, Diana Bentley and Wendy Howard.

\section{Contact:}

diana.bentley@health.nsw.gov.au or wendy.howard@health.nsw.gov.au

\section{References}

1. Garling P. Final Report of the Special Commission of Inquiry: Acute Care in NSW Public Hospitals [Internet]. Sydney: State of NSW: 2008 [cited 2020 May 6]. Available from: www.dpc.nsw.gov.au/assets/dpc-nswgov-au/publications/Acute-Care-Servicesin-NSW-hospitals-listing-437/7d979f4786/ Overview-Special-Commission-of-Inquiryinto-Acute-Care-Services-in-NSW.pdf.

2. Litak D. Colour coding scrubs as a means of improving perioperative communication. J Perioper Pract 2011;21(5):177-178.

3. PatientSafe Network. \#TheatreCapChallenge: Where's the evidence? [Internet]. Sydney: PatientSafe Network; 2020 [cited 2020 May 6]. Available from: www.psnetwork.org/ theatrecapchallenge-wheres-the-evidence/.

4. Hodge B. Beginner's guide: The most important project team member the project champion [Internet]. ProjectNewsToday; 2017 [cited 2020 May 6]. Available from: projectnewstoday.com/project-champion/.

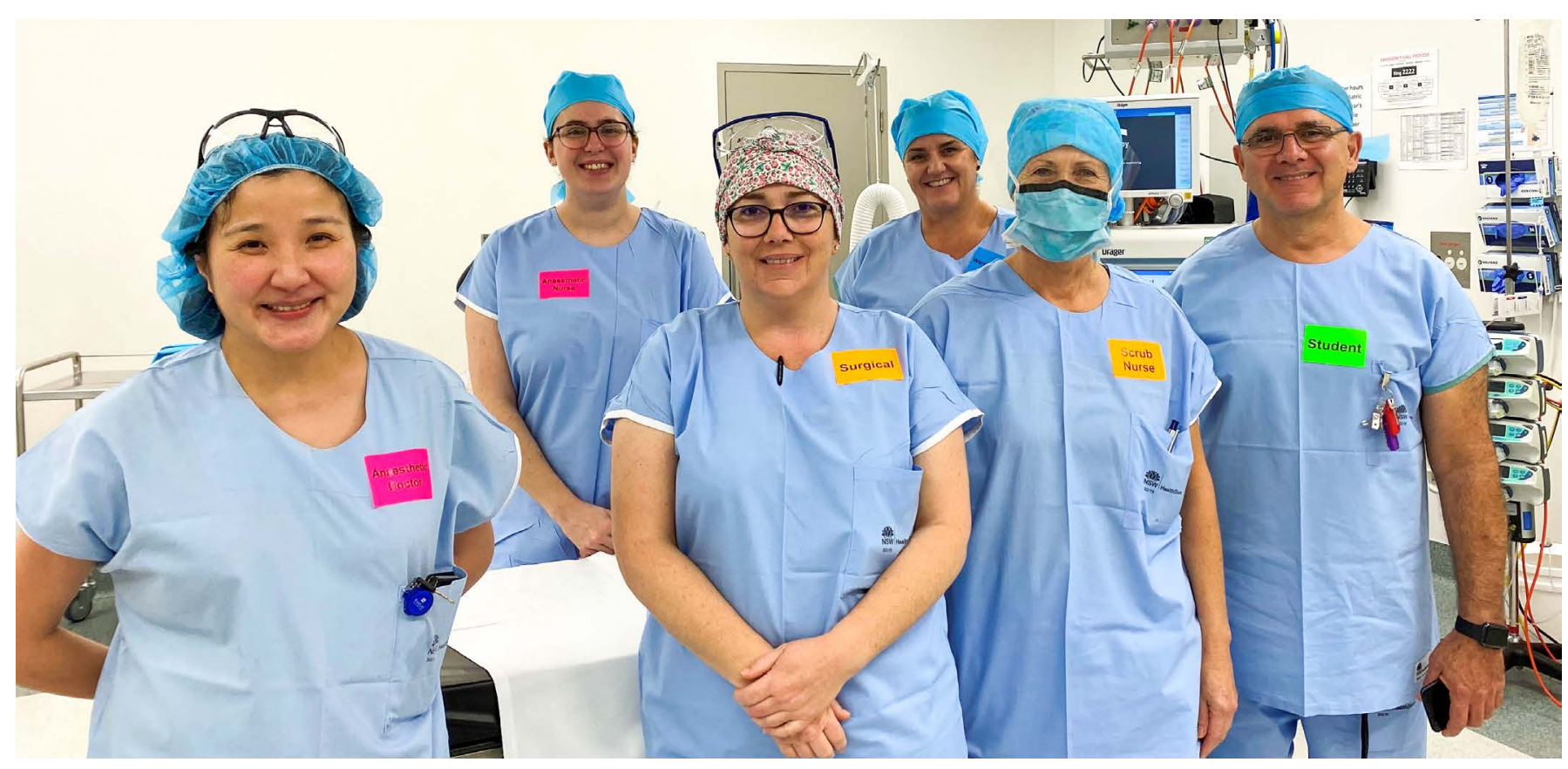

Perioperative team wearing colour-differentiated ID labels 